\title{
THE CONCENTRATION OF CHOLESTEROL IN THE BLOOD SERUM OF NORMAL MAN AND ITS RELATION TO AGE ${ }^{1}$
}

\author{
By ANCEL KEYS, OLAF MICKELSEN,2 ERMA v. O. MILLER, E. RUSSELL HAYES, \\ AND RAMONA L. TODD \\ (From the Laboratory of Physiological Hygiene, School of Public Health, University of Min- \\ nesota; and the Students' Health Service and the Department of Medicine, \\ University of Minnesota, Minneapolis)
}

(Submitted for publication March 16, 1950; accepted, July 18, 1950)

Measurements of blood cholesterol are ordinarily made for the purpose of comparing the values obtained for the particular individuals, usually prospective or actual patients, with some reference standard. In most cases the reference standard is a value or range of values supposed to represent the "normal" person; sometimes the reference point is a value obtained on some previous occasion from the individual in question. In the latter case, the assumption is implicit that the natural variability of the individual is either negligible or is taken into account in the interpretation; in practice this assumption is seldom warranted. In the former case, the same assumption enters but an additional assumption is that there is, in fact, a valid reference standard at hand and that this properly defines the normal person or population with which the examinee is to be compared.

Scrutiny of the literature, however, suggests that the basic data so far available are inadequate for these reference purposes except where very large deviations are involved. The present paper attempts to provide the bases for more precise evaluation of total blood serum cholesterol determinations in persons of various ages. For this purpose we have made about 5000 measurements of serum total cholesterol on 2056 persons known to be physically "normal." These data were obtained in two independent research projects covering the years 1947-1949. In the Laboratory of

1 The work reported here was aided by grants from the National Dairy Council, acting on behalf of the American Dairy Association, Chicago, and from the B. F. Nelson Research Fund, Minneapolis. The subjects studied in the Laboratory of Physiological Hygiene were available in connection with a long-range research project sponsored by the U. S. Public Health Service on the recommendation of the Cardiovascular Study Section.

2 Now in the Division of Chronic Diseases, U. S. Public Health Service, Washington, D. C.
Physiological Hygiene studies on blood cholesterol were a part of a long-range analysis of the quantitative characteristics of the individual and their change with age; in the Students' Health Service cholesterol measurements were incorporated in a cross-sectional survey. The two sets of data were, to some extent, complementary but they both included large numbers of young men of the same age. Comparison of the findings on the two samples for the same age groups showed them to be in very close agreement and, accordingly, data from both laboratories were pooled for the present analysis.

\section{The cholesterol methods}

In the Students' Health Service (SHS) the Schoenheimer-Sperry method (1) was used throughout. In the Laboratory of Physiological Hygiene the LiebermannBurchard reaction was applied to the Bloor extract but occasionally the Schoenheimer-Sperry method was also used on duplicate serum samples.

On several occasions during the collection of these data LPH and SHS exchanged sets of blood samples for independent check of the two methods as used in the two laboratories. The average disparity between the two laboratories in these checks (LPH-SHS) was +2.1 (S.D. $= \pm 10.4$ ) mg. per $100 \mathrm{ml}$; ; this corresponds to a mean agreement within $1.1 \%$ of the average value for the serum samples exchanged.

In LPH the Liebermann-Burchard reaction was applied with small modification from the procedure outlined in the Handbook on the Evelyn Photoelectric Colorimeter. Cholesterol standards were included in every day's run, all measurements were made in duplicate, reading was made at the point of maximum color development, and color was developed and read in a constant temperature room $\left(24^{\circ}\right.$ to $26^{\circ} \mathrm{C}$.). In a representative series of 100 consecutive blood samples in LPH the mean difference between duplicates was $4.3 \mathrm{mg}$. per $100 \mathrm{ml}$. with this method.

\section{Subjects}

The subjects aged 16 through 30 years were university students selected at random from those undergoing the 
regular medical examinations for entering students at the University of Minnesota. Their "normality" was judged from a physical and laboratory examination made at the time blood was drawn.

The men between the ages of 30 and 44 , inclusive, were, for the most part, employees of the University of Minnesota who were judged to be "normal" on the basis of a medical examination at the time. A few graduate students and local business men were included in this age group.

The men between the ages of 45 and 55 , inclusive, were local business and professional men, mostly in responsible positions, who are participants in a long-range study on the characteristics of the cardiovascular system. They were selected from 916 volunteers who responded to invitations sent to 1000 men whose names were supplied by local corporations as presumably normal "responsible citizens" in their age bracket (2). In their selection, about 60 men were rejected as being not fully normal, some others were rejected because of insufficient information, and the remainder were drawn by lot. Their clinical normality was attested by the findings in exhaustive medical examinations.

The men over 55 years of age were likewise physically "normal" but they comprised two groups. The majority were business and professional men who corresponded in mode of life to the $\mathbf{4 5}$ to 55-year-old group. There were also 20 men under treatment for mental illness; they were included here because their blood analyses showed no significant differences from the other men of the same age.

\section{Basal versus non-basal conditions}

In general, the subjects at LPH were studied under substantially basal conditions before breakfast and after 20 to 30 minutes of quiet bed rest before blood sampling. The subjects at SHS were in the resting state but were not basal; they corresponded to the condition commonly met in an out-patient clinic or consulting office.

The present study was not designed specifically to compare basal and non-basal conditions but data were obtained which provide useful information on this subject. Sixteen normal men, aged 27 to 44 years, were studied on four to seven occasions; the condition was basal rest on several occasions and at the other times blood was drawn after five to ten minutes of supine rest at two to four hours after breakfast, the intervening period being devoted to routine desk or laboratory work. On the average, the blood cholesterol level in the non-basal state was $3.8 \mathrm{mg}$. per $100 \mathrm{ml}$. of serum higher than in the basal state but the difference was statistically not significant in this small series.

For the present purposes useful information is obtained from the comparison of the results of
TABLE I

Total cholesterol concentration, in mg. per $100 \mathrm{ml}$. of serum, in 922 normal male students at the University of Minnesota as obtained in the Laboratory of Physiological Hygiene (LPH) and in the Students Health Service (SHS)

Means, standard deviations (S.D.) and standard errors (S.E.)

\begin{tabular}{c|c|c|c|c|c}
\hline \hline Age & Series & No. & Mean & S.D. & S.E. \\
\cline { 2 - 3 } $17-20$ & LPH & 109 & 173.2 & 30.2 & 2.89 \\
$17-20$ & SHS & 343 & 173.6 & 31.2 & 1.70 \\
$21-25$ & LPH & 108 & 179.5 & 36.7 & 3.53 \\
$21-25$ & SHS & 362 & 180.4 & 37.5 & 1.97 \\
\hline
\end{tabular}

the two laboratories on samples of normal young men drawn from the same student population but studied under basal conditions (LPH) on the one hand and under non-basal conditions (SHS) on the other. The data in Table I show that for men aged 17 to 20 , inclusive, the two means agreed within $0.4 \mathrm{mg}$. per $100 \mathrm{ml}$., while for the age group 21 to 25 years the disparity between the means was only $0.9 \mathrm{mg}$. per $100 \mathrm{ml}$. These differences are not statistically significant, even though the numbers involved are large. Moreover, there was no significant difference between the variability (S.D.) in the two groups. Both sets of data show a significant mean rise in cholesterol level from ages 17-20 to ages 21-25.

\section{Age and cholesterol in normal men}

Preliminary analysis of the data indicated a curvilinear relationship between age and serum

TABLE II

Regression of cholesterol on age in normal men for various age ranges

\begin{tabular}{|c|c|c|c|c|c|c|}
\hline \multicolumn{2}{|l|}{ Age } & \multirow{2}{*}{$\begin{array}{l}\text { No. } \\
\text { men }\end{array}$} & \multirow{2}{*}{$\begin{array}{l}\text { Mean } \\
\text { chol. }\end{array}$} & \multicolumn{3}{|c|}{ Regression equation } \\
\hline Range & Mean & & & $\mathbf{a}$ & $\mathbf{b}$ & $\mathbf{E}_{\mathbf{b}}$ \\
\hline $\begin{array}{l}17 \text { through } 25 \\
23 \text { through } 27 \\
25 \text { through } 30 \\
28 \text { through } 32 \\
30 \text { through } 45 \\
45 \text { through } 55 \\
50 \text { through } 60 \\
60 \text { through } 78 \\
17 \text { through } 45\end{array}$ & $\begin{array}{l}21.27 \\
24.96 \\
27.43 \\
29.85 \\
37.28 \\
49.85 \\
53.17 \\
69.26 \\
23.65\end{array}$ & $\begin{array}{r}916 \\
310 \\
205 \\
98 \\
116 \\
287 \\
145 \\
42 \\
1172\end{array}$ & $\begin{array}{l}176.70 \\
184.28 \\
192.48 \\
193.77 \\
210.36 \\
248.07 \\
251.25 \\
226.52 \\
181.90\end{array}$ & $\begin{array}{r}126.93 \\
85.94 \\
187.50 \\
252.87 \\
75.03 \\
187.75 \\
166.18 \\
430.14 \\
127.74\end{array}$ & $\begin{array}{r}2.34^{*} \\
3.94^{*} \\
0.18 \\
-1.98 \\
3.63^{*} \\
1.21 \\
1.60 \\
-2.94^{*} \\
2.29^{*}\end{array}$ & $\begin{array}{l} \pm 0.50 \\
\pm 1.45 \\
\pm 1.52 \\
\pm 2.81 \\
\pm 0.69 \\
\pm 0.86 \\
\pm 1.78 \\
\pm 1.30 \\
\pm 0.18\end{array}$ \\
\hline
\end{tabular}

Values of $a$ and $b$ pertain to the last squares equation: $\mathrm{Y}=\mathrm{a}+\mathrm{bX}$, where $\mathrm{Y}$ is cholesterol in $\mathrm{mg}$. per $100 \mathrm{ml}$. of serum and $X$ is age in attained years. $E_{b}$ is the standard error of the slope, $b$. Asterisks indicate slopes significantly different from the horizontal. 
cholesterol level which would require a third order polynomial for continuous fitting. Because there is no simple way of expressing the confidence limits to be attached to particular points in a higher order polynomial, we have elected to break the material into a succession of restricted age ranges to which linear equations can be fitted. The results from this fitting of successive straight lines by the method of least squares are summarized in Table II.

The relation between age and cholesterol ranges from a mean rise of $3.94 \mathrm{mg}$. per year between ages 23 and 27 to a mean fall of $2.94 \mathrm{mg}$. per year between ages 60 and 78 . Comparison of these slopes (column b in Table II) with the standard errors of the slopes (column $E_{b}$ in Table II) shows significant departures from zero slope except between the ages of 45 and 60 years, where the curvature is changing from positive to negative, and between the ages of 25 and 32 years, where the progression of cholesterol with age seems to be halted for a few years. It will be observed that, for some purposes, a single straight line, with a slope of $2.29 \mathrm{mg}$. of cholesterol per year, may be used to characterize the entire range of 17 through 45 years.

The data in Table II indicate the age ranges which may be grouped to construct a table of norms and they provide an adequate basis for adjustment to specified ages. It is justifiable to pool the data for contiguous ages over regions of age in which there is no significant change in slope and to adjust the observed means to the nearest exact ages desired for a table by the values of the slope which pertain to these particular ages. This procedure has been followed to produce the mean values in Table III. For each age value in the table the data used in the pool came from men whose actual mean age was very close-within 0.5 years except at age 75 - to the tabular age, so the adjustment of the mean cholesterol to the tabular age was very small; with this arrangement any uncertainty of the slope (indicated by $E_{b}$ ) has a negligible effect.

Measures of variability of the individuals at given ages are essential to establish the fiducial limits about these means. The standard deviations of the several age groups might be used for this purpose directly but they would over-estimate the variability for any particular year to the ex- tent that there is an age relation present; in addition to the actual variability at the given year they would include the variability resulting from the inclusion of men of different ages. Obviously, it would be desirable to use standard deviations for single years.

The present series, though rather large in total number of individuals, does not contain adequate numbers (at least 25) at single years except at ages 17 to 26 and 45 to 54 . The expedient was therefore adopted of pooling several years and adjusting the cholesterol concentrations by means of the regression equation fitted to those years.

Table III gives the cholesterol ranges for each age within which $90 \%$ and $98 \%$ of population of normal men comparable to the Minnesota population will be found. For example, only $5 \%$ of normal men aged 18 may be expected to have values less than $118 \mathrm{mg}$. per $100 \mathrm{ml}$., and only $1 \%$ of normal men aged 50 may be expected to have values exceeding $354 \mathrm{mg}$. per $100 \mathrm{ml}$. The assignment of particular cholesterol values to "normal" or "abnormal" categories may be made by reference to Table III, provided there is clear understanding of the definition of these terms. If it is agreed that values which may be expected in less than $5 \%$ of a normal population are "possibly

TABLE III

Fiducial limits for total cholesterol, in mg. per $100 \mathrm{ml}$. of serum, in normal males

\begin{tabular}{|c|c|c|c|c|c|c|c|c|}
\hline \multirow{2}{*}{ Age } & \multirow{2}{*}{$\mathbf{N}_{\mathbf{2}}$} & \multirow{2}{*}{ Mean } & \multirow{2}{*}{$\mathrm{N}_{2}$} & \multirow{2}{*}{ S.D. } & \multicolumn{4}{|c|}{ Population limits } \\
\hline & & & & & \multicolumn{2}{|c|}{$90 \%$} & \multicolumn{2}{|c|}{$98 \%$} \\
\hline $\begin{array}{l}18 \\
20 \\
25 \\
30 \\
35 \\
40 \\
45 \\
50 \\
55 \\
60 \\
65 \\
70 \\
75\end{array}$ & $\begin{array}{r}203 \\
781 \\
310 \\
160 \\
91 \\
150 \\
77 \\
287 \\
90 \\
69 \\
45 \\
42 \\
19\end{array}$ & $\begin{array}{l}168.2 \\
173.7 \\
184.4 \\
195.1 \\
200.4 \\
219.4 \\
235.5 \\
248.3 \\
255.7 \\
253.3 \\
236.7 \\
224.6 \\
211.8\end{array}$ & $\begin{array}{r}168 \\
145 \\
163 \\
142 \\
56 \\
62 \\
98 \\
98 \\
90 \\
69 \\
45 \\
42 \\
20\end{array}$ & $\begin{array}{c}30.7 \\
32.0 \\
34.0 \\
40.3 \\
43.1 \\
38.6 \\
37.2 \\
44.8 \\
45.6 \\
33.6 \\
34.3 \\
41.5 \\
(36.9)\end{array}$ & $\begin{array}{l}118 \\
121 \\
128 \\
129 \\
128 \\
154 \\
174 \\
174 \\
180 \\
197 \\
179 \\
155 \\
148\end{array}$ & $\begin{array}{l}219 \\
226 \\
240 \\
261 \\
272 \\
284 \\
297 \\
323 \\
332 \\
309 \\
294 \\
294 \\
276\end{array}$ & $\begin{array}{r}97 \\
99 \\
105 \\
101 \\
97 \\
127 \\
147 \\
142 \\
148 \\
173 \\
154 \\
124 \\
118\end{array}$ & $\begin{array}{l}240 \\
248 \\
264 \\
289 \\
303 \\
312 \\
324 \\
354 \\
364 \\
333 \\
320 \\
325 \\
306\end{array}$ \\
\hline
\end{tabular}

Ages are exact attained ages in years; linear interpolation between tabular years is permissible. $N_{1}$ is the number of men used to determine the mean; $\mathrm{N}_{2}$ is the number of men used to determine the standard deviation (S.D.). Under the headings $90 \%$ and $98 \%$ will be found the limits within which will occur, respectively, $90 \%$ and $98 \%$ of the population of indicated age. 
abnormal" and those which occur in only $1 \%$ are to be considered "probably abnormal," then a value of $300 \mathrm{mg}$. in a 45-year-old man should be labelled as only "possibly abnormal" but in a 30year-old man it would be "probably abnormal." Incidentally, a value of $320 \mathrm{mg}$. would then be accepted as definitely within normal limits for men of 50 and 55 years of age.

\section{Inter-individual variability}

The detailed analysis of the inter-individual variability cannot be recapitulated in the present space but the main findings may be noted. Firstly, it was found that the absolute variability is not homogeneous over the entire age range ( $\mathrm{L}$ ratio) (3) ; absolute variability between individuals is maximal in the fourth and sixth decades of life and is minimal below the age of 30 years. Secondly, the relative variability (expressed as a percentage of the mean) is more homogeneous at different ages but there is a distinct tendency for the scatter to be large in the thirties and small in the middle forties and the early sixties. For example, the relative standard deviation is $20.66 \%$ $( \pm 1.23)$ at age $30 ; 15.80 \%( \pm 1.13)$ at age 45 ; and $13.26 \%( \pm 1.13)$ at age 60 . Special researches would be required to discover the biological significance of these facts.

\section{The frequency distribution}

All of the statistical analyses here have assumed a normal (Gaussian) probability distribution of the cholesterol values. Although moderate degrees of skewness or kurtosis would not seriously disturb these calculations, it is desirable to examine this question. Detailed analysis by the calculation of the third and fourth moments about the means for the several age groups failed to disclose significant departures from a normal frequency distribution.

\section{Sex, age, and serum cholesterol}

For the comparison of normal males and females with regard to age and cholesterol concentration in the serum we have satisfactory measurements on 1,611 individuals between the ages of 17 and 30 , inclusively. The essential data are summarized in Table IV.

The substantial identity of the two sexes in regard to cholesterol is apparent from Table IV.
TABLE IV

Sex and cholesterol. Comparison of 1047 normal males $(M)$ and 564 normal females $(F)$ between the ages of 17 and 30, inclusive

\begin{tabular}{|c|c|c|c|c|c|c|}
\hline \multirow{2}{*}{ Item } & \multirow{2}{*}{ Mean } & \multirow{2}{*}{ S.D. } & \multirow{2}{*}{ S.E. } & \multicolumn{3}{|c|}{ Equation } \\
\hline & & & & $\mathbf{a}$ & b & $\mathbf{E}_{\mathbf{b}}$ \\
\hline $\begin{array}{l}\text { M, Age } \\
\text { M, Chol. }\end{array}$ & $\begin{array}{r}22.07 \\
178.87\end{array}$ & $\begin{array}{l} \pm 3.09 \\
\pm 33.91\end{array}$ & $\pm \overline{1.05}$ & $\overline{126.0}$ & $\overline{2.395}$ & $\pm \overline{0.332}$ \\
\hline $\begin{array}{l}\text { F, Age } \\
\text { F, Chol. }\end{array}$ & $\begin{array}{r}21.34 \\
176.51\end{array}$ & $\begin{array}{l} \pm 2.99 \\
\pm 31.17\end{array}$ & $\pm \overline{1.31}$ & $\overline{134.4}$ & $\overline{1.975}$ & $\pm \overline{0.432}$ \\
\hline
\end{tabular}

Age in years, cholesterol (Chol.) in $\mathrm{mg}$. per $100 \mathrm{ml}$. of serum. The values of $a, b$ and $E_{b}$ refer to the constants in the least squares equation Chol. $=a+b$ (Age) and the standard error of the slope, $\mathrm{E}_{\mathrm{b}}$.

The difference of 0.42 between the slopes of the two regression lines is not statistically significant; the mean standard error of the combined slopes, weighted according to numbers, is \pm 0.373 , that is, almost as large as the difference between slopes $\left(t=1.27, t_{0.20}=1.282\right)$. Both slopes, however, are highly significantly different from zero slope. The close agreement for the two sexes is more striking when both series are adjusted to the identical mean age of 22.00 years; we have used the appropriate regression equations (cf. Table IV) for this purpose. At this point of 22.00 years the mean cholesterol values prove to be 178.70 (S.D. $= \pm 33.91$ ) for males and 177.81 (S.D. $= \pm 31.17)$ for females.

From the foregoing it is clear that, over this age range of 17 through 30 years and with this Minnesota population, there is no significant difference in serum total cholesterol between normal males and females in regard to the absolute mean, the variability between individuals, or the age trend. For predictive purposes, as in estimating normal fiducial limits, it would be entirely proper to combine the sexes for these ages.

\section{Age and cholesterol in the literature}

The opinion, generally expressed in textbooks and reviews, that there is no relation between the serum cholesterol concentration and age in adults seems to depend mainly on the report of Page and his associates (4). The men studied by them were simply stated to be, without further elaboration, "clinically normal," and there is no other indication of their general status, activity, or relative obesity. One man, excluded from their calcu- 
lations, was markedly hyperlipemic and there were no data on total cholesterol in one man, so there remain 65 observations for consideration. Page and his coworkers apparently assumed that if there were a relation between age and cholesterol concentration it must be linear over the entire age range. From the statistical treatment used, the authors were entitled to conclude that they could not prove the existence of such a linear relation.

We have regrouped the data of Page and his colleagues in three successive age groups: 21 to 51 years ( 22 men), 52 to 71 ( 21 men), and 72 years and older ( 22 men). The means and standard errors of these groups prove to be, respectively, $224.4 \pm 11.2,244.3 \pm 13.2$, and $232.4 \pm$ $12.4 \mathrm{mg}$. of total cholesterol per $100 \mathrm{ml}$. of serum. Though these age groupings are rather unsatisfactory in view of the age trend indicated from our own studies, the general picture is not dissimilar; the highest value is that for the men of middle to old age, the loweșt that for the younger men, and the very old men are intermediate.

The researches of Bürger and Möbius (5) and of Barker (6) provide data which are relevant though not suitable for statistical analysis; they are summarized in Table V. Both sets of data are roughly in agreement with our own findings; there is a progressive rise from youth through middle age and a distinct decline in old age.

The recent data of Collen (7) likewise support the conclusion that there is a relation between age and serum cholesterol in normal man. Though Collen made no detailed analysis, the raw data may be read off from his Graph 1. Statistical analysis of these figures reveals a mean total cholesterol concentration in the serum of 242.0 (S.E. $= \pm 6.17$ ) mg. per $100 \mathrm{ml}$. for 36 normal men aged 30 to 39 years and a mean of 254.2

TABLE $\mathbf{v}$

Mean total cholesterol concentrations in blood serum (mg. per $100 \mathrm{ml}$.) of normal persons of different ages

Series A from Bürger and Möbius, Series B from Barker.

\begin{tabular}{l|r|r|r|r|r|r|r|r}
\hline \multicolumn{1}{c|}{ Decade } & \multicolumn{1}{c|}{2} & 3 & \multicolumn{1}{c|}{4} & 5 & 6 & 7 & 8 & 9 \\
\hline A no. & 9 & 11 & 10 & 10 & 11 & 11 & 4 & 2 \\
A Chol. & 149 & 168 & 214 & 212 & 199 & 189 & 178 & 162 \\
B no. & 3 & 66 & 53 & 41 & 25 & 11 & 1 & \\
B Chol. & 160 & 203 & 215 & 232 & 244 & 233 & 172 & \\
\hline
\end{tabular}

$(\mathrm{S} . \mathrm{E} .= \pm 10.81)$ for 25 normal men aged 40 to 59 years.

Further support can be claimed from the study of Eck and Desbordes (8) on 30 "normals." When these subjects are divided into groups of 15 younger (mean age 26.1 years) and 15 older (mean age 55.0 years) subjects, the means and standard errors are, respectively, $150.7 \pm 4.5$, and $181.3 \pm 13.5 \mathrm{mg}$. per $100 \mathrm{ml}$. This difference of $30.6 \mathrm{mg}$. is statistically significant $\left(t=2.15 ; t_{0.05}\right.$ $=2.048$ ).

There are a few studies of old people which, because of small numbers or failure to provide essential data and controls at other ages, are of very limited value [Aaltonen (9) ; Rafsky and Newman (10); Foldes and Murphy (11); Björk and Karni (12)]. Brodin, Aubin and Grigaut (13) concluded their 61 aged persons showed a progressive diminution of serum cholesterol with age.

Shortly after this paper was completed there appeared a paper by Kornerup (14) containing cholesterol values in normal persons in Denmark. The values for 54 males from 19 through 46 years are suitable for regression analysis. For these 54 men the mean age was 29.9 years and mean total cholesterol was $202.96 \mathrm{mg}$. per $100 \mathrm{cc}$. of serum. The least squares equation proves to be: cholesterol $=155.1+1.601$ times age in years. The standard error of the slope $= \pm 0.703$ and the ratio of the slope to its error $=2.28$. Neither the mean value (for age 30 ) nor the age slope is significantly different from the Minnesota findings. This new Danish material, in other words, provides further evidence for the general validity of the Minnesota data.

\section{General comment}

The combined evidence here and in the literature points rather clearly to rising values for serum cholesterol from youth through middle age and to lower values in the oldest persons in the population samples. This does not necessarily mean, however, that the cholesterol level actually declines in old age. These oldest persons, including those examined in the present study, are obviously the survivors of a population from which many persons departed this life before attaining advanced ages. The survivors whose bloods were examined may not have been typical, at younger ages, of the general population. It is entirely pos- 
sible that persons who are individually characterized by having relatively low cholesterol concentrations tend to survive longer than their fellows who maintain higher levels. This is an intriguing and important problem which deserves the most careful study.

The values given here in Table III must be recognized for what they are, that is, the best estimates we can provide for a population and environment such as involved here-clinically normal persons from a somewhat superior economic bracket in a metropolitan community, not engaged in manual labor but actively engaged in a gainful occupation, living in a cool temperate environment and subsisting on the varied and somewhat luxurious diets common to the upper Midwest. From comparisons with the data in the more recent literature it seems that these or very similar values would be pertinent to many other population groups, at least in the United States and in Denmark.

Finally, as in any other set of norms derived in this way, it is important to differentiate between the average and the optimum. The present findings show the means and fiducial limits for "normal" people as they are and not necessarily as they should be. It may be that the most "popular" cholesterol values, in the sense of being most frequently found, are the best; it is equally possible that other values would be more conducive to the maintenance of health and longevity. Long-range, longitudinal studies will be required to settle such points.

We have pointed out the fact that the results in the two laboratories, using two different methods, were substantially identical. This does not necessarily mean, however, that the two methods give identical results or that there is absolutely no difference between the cholesterol concentrations in the basal and in the non-basal states. A small tendency for nonbasal values to exceed basal values could be offset by an opposite small tendency for the SHS method to give lower values than the LPH method. The general magnitude of these differential tendencies seems to be of the order of $5 \mathrm{mg}$. per $100 \mathrm{ml}$., that is, a difference which is unimportant for most purposes. It would be most precise, however, to state that the cholesterol values given in the several tables in this paper apply either to basal conditions and the
LPH method or to non-basal conditions and the SHS method; slightly lower values would probably apply to the SHS method applied to bloods drawn under basal conditions.

\section{The "normality" of the individual}

In the present paper we have provided a quantitative description of the concentration of total cholesterol in the serum for a certain population. Given a cholesterol measurement on an individual, it is readily possible to estimate the likelihood that the measurement conforms to the expectations for an individual of the same age drawn at random from this reference population. Elsewhere we have discussed the problem of the more complete analysis of cholesterol standards (15). U1timately the problem is to "explain," or account for quantitatively, the finding in any individual. Besides age, other factors for early consideration include basal metabolism, relative obesity, the total energy metabolism, and the character of the customary diet. These are currently under investigation and it may be that their proper analysis will further reduce the unexplained variation between individuals who are clinically normal. However, this will not automatically answer the question as to the prognostic significance of a given cholesterol value. The distinction between normal and optimal standards must be clearly recognized.

\section{SUM MARY}

1. Measurements of total serum cholesterol concentration were made on 1,492 men from 17 to 78 years old and on 564 women from 17 to 30 years old. These persons were judged to be physically normal from detailed examinations. With few exceptions they represented the more responsible element of the population in an upper Midwestern metropolitan area and were engaged in business, professional, and scholastic pursuits.

2. Both Schoenheimer-Sperry (digitonin) and Bloor extract Liebermann-Burchard methods were used with close agreement between the results.

3. Over the age range 17 to 30 the cholesterol values for men and women were not significantly different as to averages, individual variability, and age trend. Over this age range there was an average increase, per year of age, amounting to $2.2 \mathrm{mg}$. of total cholesterol per $100 \mathrm{ml}$. of serum. 
4. The cholesterol data for limited age ranges were shown to conform to normal (Gaussian) frequency distribution.

5. For the age range 17 to 78 years in men there was a pronounced curvilinear relation between age and serum cholesterol concentration with a maximum in the sixth decade. By fitting a succession of least square straight lines, a standard table was constructed for means and standard deviations and for fiducial limits for $90 \%$ and for $98 \%$ of the population.

6. At all ages above 35 years, $1 \%$ of such "normal" men exceed $300 \mathrm{mg}$; over the range of 45 to 70 years, $1 \%$ will exceed $320 \mathrm{mg}$. Between the ages of 45 and $60,5 \%$ of normal men exceed $300 \mathrm{mg}$.

7. Analysis of published data demonstrated substantial agreement with the age relation found here in spite of previous conclusions in the literature to the contrary.

\section{ACKNOWLEDGMENTS}

Mrs. Evelyn Woltjen made the cholesterol measurements in the Students' Health Service and Miss Betty J. Berline made the initial statistical preparation of that material. Mrs. Nedra Foster and Miss Laura Werner helped in several phases of the work in the Laboratory of Physiological Hygiene. Mr. Norris Schulz helped in the computations and $\mathrm{Mr}$. Kenneth Tiede assisted in some of the elaborate statistical treatment with the combined data. We are grateful to Dr. Josef Brozek for useful discussions on the statistical problems. We are indebted for help in obtaining some of the subjects to Doctors Ralph Rossen, David State, L. F. Richdorf, and Austin Henschel.

\section{BIBLIOGRAPHY}

1. Schoenheimer, R., and Sperry, W. M., A micromethod for the determination of free and combined cholesterol. J. Biol. Chem., 1934, 106, 745.
2. Keys, A., Mode of life and the development of heart disease: research for a preventive hygiene. Chicago Heart Assoc. Bull., 1948, 26, 3.

3. Neyman, J., and Pearson, E. S., On the problem of $K$-samples. Bull. Acad. Polon. Sci. Lettres, Sér. A., 1931, 460.

4. Page, I. H., Kirk, E., Lewis, W. H., Jr., Thompson, W. R., and Van Slyke, D. D., Plasma lipids of normal men at different ages. J. Biol. Chem., 1935, 111, 613.

5. Bürger, M., and Möbius, W., Der Jod- und Cholesteringehalt des Blutes in seinen Beziehungen zur essentiellen Hypertonie. Klin. Wchnschr., 1934, 13, 1349.

6. Barker, N. W., The plasma lipoids in arteriosclerosis obliterans. Ann. Int. Med., 1939, 13, 685.

7. Collen, M. F., Blood cholesterol studies in coronary artery disease. Permanente Found. M. Bull., 1949, 7, 55.

8. Eck, M., and Desbordes, J., Influence de l'âge sur les variations de la cholestérinémie et due pouvoir cholestérolytique. Compt. rend. Soc. de biol., 1935, 118, 498.

9. Aaltonen, K. E., Klinische Beobachtungen an Greisen, die das achtigste Lebensjahr vollendet haben. Acta med. Scandinav., 1939, 99, 356.

10. Rafsky, H. A., and Newman, B., Cholesterol studies in the aged. J. Lab. \& Clin. Med., 1942, 27, 1563.

11. Foldes, F. F., and Murphy, A. J., Distribution of cholesterol, cholesterol esters and phospholipid phosphorus in normal blood. Proc. Soc. Exper. Biol. \& Med., 1946, 62, 215.

12. Björck, G., and Karni, H., Kolesterinaemi vid hjärtsjukdomar. Nord. Med., 1948, 38, 1175.

13. Brodin, P., Aubin, A., and Grigaut, A., Recherches sur le chimisme sérique, les éléments figurés du sang et la vitesse de sédimentation des hématies chez le vieillard. La Presse Méd., 1937, 1, 641.

14. Kornerup, V., Concentrations of cholesterol, total fat and phospholipid in serum of normal man. Arch. Int. Med., 1950, 85, 398.

15. Keys, A., The physiology of the individual as an approach to a more quantitative biology of man. Federation Proc., 1949, 8, 523. 